\title{
The effects of aerobic activity on brain structure
}

\author{
Adam G. Thomas ${ }^{1,2 *}$, Andrea Dennis ${ }^{2}$, Peter A. Bandettini ${ }^{1,3}$ and Heidi Johansen-Berg ${ }^{2}$ \\ Functional MRI Facility, NIMH, NIH, DHHS, Bethesda, MD, USA \\ ${ }^{2}$ Clinical Neurology, FMRIB, University of Oxford, Oxford, UK \\ ${ }^{3}$ Section on Functional Imaging Methods, NIMH, NIH, DHHS, Bethesda, MD, USA
}

Edited by:

David L. Wright, Texas A\&M

University, USA

Reviewed by:

Karen Zentgraf, University of

Muenster, Germany

Keith Lohse, University of Colorado

at Boulder, USA

${ }^{*}$ Correspondence:

Adam G. Thomas, National Institutes

of Health, 10 Center Drive, Room

1D80, Bethesda, MD 20892-1148,

USA.

e-mail: adamt@nih.gov
Aerobic activity is a powerful stimulus for improving mental health and for generating structural changes in the brain. We review the literature documenting these structural changes and explore exactly where in the brain these changes occur as well as the underlying substrates of the changes including neural, glial, and vasculature components. Aerobic activity has been shown to produce different types of changes in the brain. The presence of novel experiences or learning is an especially important component in how these changes are manifest. We also discuss the distinct time courses of structural brain changes with both aerobic activity and learning as well as how these effects might differ in diseased and elderly groups.

Keywords: exercise, plasticity, hippocampus, neurogenesis, angiogenesis, learning, environmental enrichment, aging

\section{INTRODUCTION}

The benefits of exercise and physical fitness on mental health and cognitive performance are well documented (for reviews see Cotman and Berchtold, 2002; Colcombe and Kramer, 2003; Vaynman and Gomez-Pinilla, 2005; Cotman et al., 2007; Kramer and Erickson, 2007; Chaddock et al., 2010). There is also a rich literature dating back at least 70 years from animal studies documenting the profound structural changes in the brain produced by complex or enriched environments. These structural changes include, but are not limited to, synaptic size and density, complexity and extent of dendritic arbors, size and number of glial processes, vascular density, and rate of neurogenesis (for reviews see Markham and Greenough, 2004; Pearson-Fuhrhop et al., 2009). Animal studies have also demonstrated that exercise or physical activity produces very specific changes in the brain that are distinct from those produced by learning or novel experiences (Black et al., 1990).

Recently, studies have been carried out in humans using noninvasive brain imaging techniques to investigate exercise-related changes in brain structure (Erickson et al., 2009, 2011; Chaddock et al., 2010). Such studies provide compelling evidence for the powerful effects of exercise on the brain, but also raise several questions. For example, do structural changes occur throughout the brain or are they limited to specific brain regions? What aspects of brain architecture are specifically modified by physical activity? On what time scale do these changes occur, and how persistent are they when exercise is discontinued? Do specific preconditions such as aging, disease, or genetic phenotypes make individuals more or less susceptible to activity-based brain changes? This review will explore these questions as well as future directions in the study of the effects of physical activity on the brain.

Several different methodologies have been employed to investigate these questions. Many studies have been conducted on rodents using histological techniques. These studies provide an extremely detailed picture of the kinds of brain changes that occur with exercise. However, they are limited in that they require researchers to pre-select a specific region of the brain for slicing and staining. They also do not afford the ability to utilize a truly longitudinal design, as the measurements require the animals to be sacrificed. A second body of literature has used neuroimaging techniques to investigate exercise-related changes in human participants. While these studies provide less direct measurements of the underlying changes in neural tissues, they have the advantage of allowing researchers to look for changes throughout the brain. These studies are also amenable to longitudinal designs, which can more clearly establish causality of structural changes.

\section{WHAT IS "PHYSICAL ACTIVITY"?}

Physical activity is defined as bodily activity that results in energy expenditure above resting levels (US Department of Health and Human Services, Centers for Disease Control and Prevention, National Center for Chronic Disease Prevention and Fitness, President's Council on Physical Fitness, 1998). Exercise refers to physical activity that is structured to meet specific fitness gains (Caspersen et al., 1985). Maintaining a physically active lifestyle has been associated with a vast range of positive health outcomes that include benefits to cognitive function (Cancela Carral and Ayán Pérez, 2007; Cassilhas et al., 2007; Kramer and Erickson, 2007; Smiley-Oyen et al., 2008; Smith et al., 2010; Ruscheweyh et al., 2011). The American College of Sports Medicine recommends that most adults engage in a regular exercise regime in order to maintain health and wellbeing, suggesting that higher activity levels are associated with greater health outcomes (Haskell et al., 2007). The current guidelines for optimal health and fitness recommend that adults engage in moderate-intensity exercise training for $\geq 30$ min per day on $\geq 5$ days a week, or vigorousintensity training for $\geq 20$ min a day on $\geq 3$ days a week, or a combination of moderate- and vigorous-intensity exercise. In addition, it is also recommended that individuals devote 2-3 days per week to resistance exercises for each of the major muscle groups, as well as neuro-motor exercises (balance, agility, 
and coordination) and flexibility exercises for each the major muscle-tendon groups.

Moderate-intensity exercise refers to exercising at sub-maximal workloads, during which energy is supplied by the aerobic energy system. Exercising within this zone results in a host of physiological responses to the increased metabolic demand for oxygen by the skeletal muscle, skin, and brain. Prolonged training at moderate aerobic intensities results in physiological adaptations, including increased blood volume, capillary density, mitochondrial size and density, improved fat mobilization, and thermoregulation. Collectively these adaptations represent improved cardio-respiratory fitness. This fitness can be quantified by measuring the maximum rate at which an individual can take up and utilize oxygen, known as the "ن் $\mathrm{V}_{2}$ max" (Åstrand et al., 2003). $\dot{\mathrm{V} O} 2$ max can be increased with aerobic training, but this effect is modulated by several factors, including the age, the initial level of aerobic fitness, and the intensity, frequency, and duration of training. The greatest increases in $\dot{\mathrm{VO}}_{2}$ max are generally observed in previously sedentary individuals. Aerobic training for improved cardiorespiratory fitness is typically performed between 65 and $85 \%$ of an individual's $\dot{\mathrm{V}}_{2}$ max.

Vigorous-intensity exercise involves training above $85 \%$ of $\dot{\mathrm{V}} \mathrm{O}_{2}$ max, during which energy is supplied by the anaerobic energy system. Such high-intensity exercise requires rapid re-synthesis of ATP to provide energy for muscular contraction. The demand for this energy exceeds the rate at which oxygen delivery and consumption can support it. As a result, this type of exercise is limited by a finite capacity for energy production. Once this limit is reached, fatigue results and the exercise must either cease or be reduced in intensity. Training at this intensity, as with resistance training, results mainly in peripheral adaptations to the muscles being stressed as well as a strengthening of the neuromuscular mechanisms for movement.

The effects of anaerobic (Winter et al., 2007), resistance (Lachman et al., 2006; Cassilhas et al., 2007; Busse et al., 2008), and flexibility training (Erickson et al., 2011) on brain structure have been explored, yet the results remain equivocal. The majority of studies on the effects of physical activity on brain structure have focused on aerobic or moderate-intensity exercise (Colcombe et al., 2006; Voss et al., 2010). The frequency and the duration of the training intervention required for brain plasticity remains vague. Similarly, it is not clear whether an increase in aerobic fitness (as indicated by increased $\dot{\mathrm{V}} \mathrm{O}_{2} \max$ ) is necessary to effect changes to the brain's morphology or cognitive processes. For example, it may be possible that the simple stimulus of increased cerebral blood volume (CBV) during exercise is enough to drive the changes.

\section{WHERE IN THE BRAIN DO STRUCTURAL CHANGES OCCUR?}

Environmental enrichment in rodents has been shown to produce structural changes in several distinct regions of cerebellar and cerebral cortex (Markham and Greenough, 2004). To date, however, these methods have only demonstrated exercise-related structural change in motor areas, such as the cerebellum and motor cortex, and in specific regions within the hippocampus, which plays a prominent role in learning, memory, and navigation. Human imaging studies have at times complemented these findings in specific regions, while in other cases they have found global changes in brain structure.

\section{CEREBELLUM AND MOTOR CORTEX}

In a rodent study, Black et al. (1990) contrasted effects of aerobic exercise and motor learning. Specifically, while 30 days of wheel running produced an increase in capillary density, 30 days of traversing an acrobatic maze produced an increase in the number of synapses per purkinje cell (the large, primary nerve cell in the cerebellum). Subsequent studies have demonstrated similar changes in blood vessel density in motor cortex using both histological (Kleim et al., 2002b) and magnetic resonance imaging (MRI) techniques (Swain et al., 2003).

\section{HIPPOCAMPUS}

Some of the most compelling evidence of exercise-mediated brain changes has been found in the hippocampus, a brain structure involved with memory as well as stress regulation (Kim and Diamond, 2002; Small et al., 2011). As early as 1999 it was demonstrated that wheel running dramatically increased the number of new neurons in the hippocampus of mice (van Praag et al., 1999a). Pereira et al. (2007) replicated this finding and went on to demonstrate that the number of new neurons correlated with increases in CBV, measured using contrast-enhanced MRI. The same paper showed a similar increase in CBV in a small group of middle-aged human subjects after 12 weeks of exercise training.

Chaddock et al. (2010) showed that preadolescent children with higher $\dot{\mathrm{V}} \mathrm{O}_{2}$ max scores had larger hippocampal volumes (as determined by MRI scans) than those with lower $\dot{\mathrm{VO}} 2$ max scores. Erickson et al. (2009) showed a correlation between the volume of the hippocampus and cardiovascular fitness (peak $\mathrm{VO}_{2}$ ) in a cohort of 165 older adults. A follow-up study by the same authors (Erickson et al., 2011) demonstrated that 1 year of aerobic exercise increased the volume of hippocampus by $2 \%$ in elderly adults, while controls who underwent 1 year of stretching exercises exhibited a $1.4 \%$ decrease in hippocampal volume. Similarly, Pajonk et al. (2010) reported a $12-16 \%$ increase in hippocampal size in a small group of exercising schizophrenic patients as well as in matched controls.

In summary, aerobic activity reliably induces structural change in hippocampal volume and vasculature. This high degree of plasticity is perhaps not surprising given the hippocampus' purported role in the rapid encoding of episodic memory (McClelland et al., 1995). It is also notable that the hippocampus displays dramatic volume changes in disease states such as Alzheimer's disease and depression (Steffens et al., 2000; Butters et al., 2008).

\section{GLOBAL EFFECTS?}

All of the afore-mentioned studies, including the neuroimaging studies, limited their investigations to specific regions of interest. However, it is possible that some effects of aerobic exercise on brain structure occur via a diffuse mechanism (such as globally altered blood volume) that would not produce localized effects. Some whole-brain, voxel-based morphometry (VBM) studies have reported an association between physical activity levels (Flöel et al., 2010) or an exercise intervention (Colcombe et al., 2006) and large clusters of increased gray matter density in frontal, temporal, and cingulate areas of the brain. Another recent study has shown that aerobic activity levels in elderly human subjects correlate with both the number and tortuosity of blood vessels throughout the 
brain using the relatively novel technique of magnetic resonance angiography (Bullitt et al., 2009). These studies suggest that while some regions of the brain may show localized volume changes in response to aerobic exercise, there may also be more global changes.

\section{WHAT IS CHANGING? COMPONENTS OF PLASTICITY GRAY MATTER}

The study of structural brain change in humans is currently limited to the relatively macroscopic measurements that are possible using neuroimaging techniques. This contrasts sharply with histological studies in animals that can measure cell number, density of dendrites, or even the size and shape of dendritic spines (See Figure 1). Many neuroimaging studies report changes in "gray matter density" or the overall volume of a given structure. These measures are commonly derived from segmenting T1-weighted MR images using the relative intensities of different voxels. Although these image intensities depend on the underlying tissue structure, they do not relate in a straightforward way to specific tissue components (e.g., cell density). The magnitude of these changes are typically in the range of 1-8\% (Draganski et al., 2004; Scholz et al., 2009; Erickson et al., 2011), but it is not possible to draw conclusions on which microscopic structures within gray matter are exhibiting an increase in volume.

Some insight into this question can be gleaned from animal studies. Figure 2 provides an approximate breakdown of the components of cerebral gray matter by volume based on several histologic studies (Cherniak, 1990; Syková, 1997; Braitenberg and Schüz, 1998; Chklovskii et al., 2002; Kleim et al., 2007). Note that these ratios should be taken only as a rough guide. The composition of cortical gray matter varies considerably between brain areas (Chklovskii et al., 2002) and species (Herculano-Houzel et al., 2006; Sarko et al., 2009). However, it has been consistently shown that well over $50 \%$ of gray matter is composed of the tangle of axonal, dendritic, and glial processes known as the neuropil, while vasculature accounts for no more than $5 \%$ of gray matter volume. Cell bodies account for less than $20 \%$ and the interstitial space between cells, synapses, and vessels accounts for over $20 \%$.

These ratios give us some feel for the magnitude each compartment would need to change to produce the volume changes reported in recent imaging. For example a $20 \%$ increase in the neuropil volume would be sufficient to produce the $8 \%$ global gray matter changes that have been reported. However if the change were limited to vasculature, a near doubling would be required to produce an $8 \%$ change in gray matter volume.

\section{VASCULATURE}

Angiogenesis in response to exercise is well-studied in muscle tissue (Prior et al., 2004). Angiogenesis can occur via a splitting process known as intussusception or a sprouting process in which a new branch sprouts from one capillary and merges onto another (Makanya et al., 2009). Studies on changes in the capillary density in rats were some of the first to distinguish between the effects of exercise versus learning or exposure to complex environments (Black et al., 1990). A replication and elaboration is provided in a follow-up study that dissociates increases in capillary number from increases in capillary density (Isaacs et al., 1992). Exposure to a complex environment produces an expansion of the volume of the molecular layer in the cerebellum, while the density of blood vessels remains constant. This necessarily involves an increase in the number of capillaries. However, the voluntary exercise condition results in an increase in the density of capillaries, while the volume of the molecular layer remains constant. Thus the ratio of blood vessel volume to other components of the layer has increased.

This dissociation between the effects of exercise and enrichment on angiogenesis was subsequently replicated in the rat motor cortex (Kleim et al., 1996, 2002a). The basic result of increased vasculature with exercise has also been replicated many times in motor cortex as well as striatum with both histological and imaging techniques (Swain et al., 2003; Ding et al., 2005, 2006). The magnitude of increased blood vessel density reported in the original Black et al. (1990) study was approximately 20\%, but the

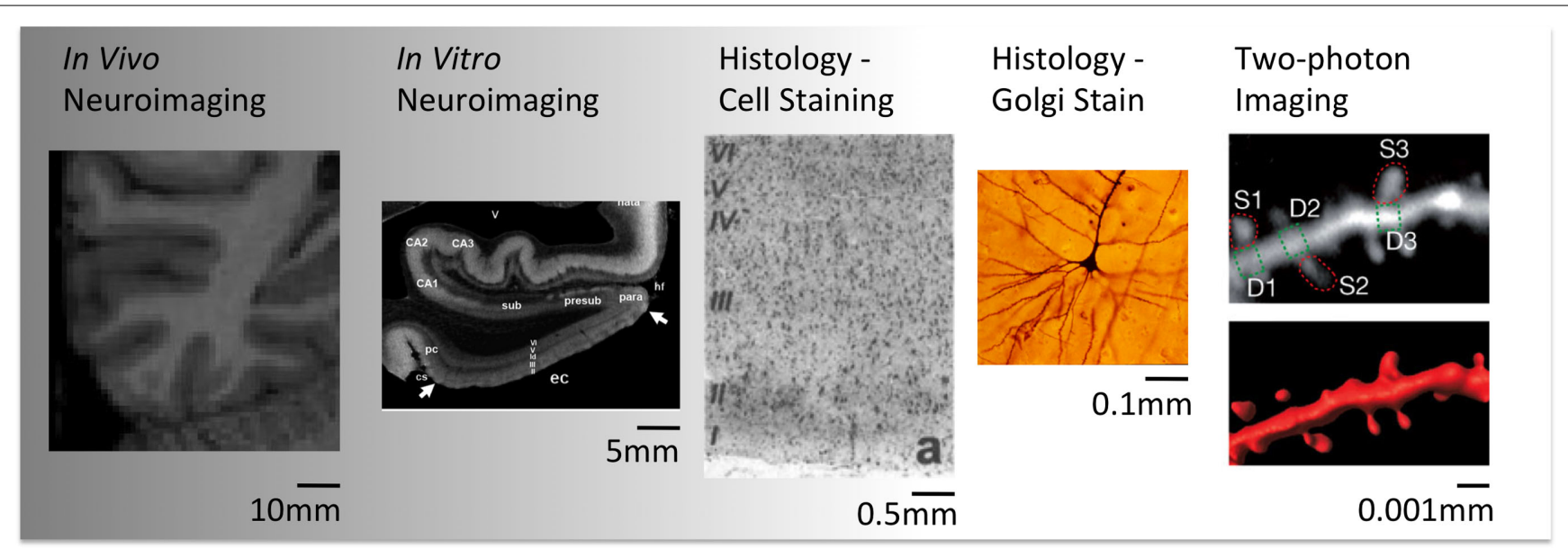

FIGURE 1 | Illustration of different spatial scales provided by different techniques (Pictures reproduced with permission. Credits: Wikimedia Commons, Arnold and Rioux, 2001; Chen et al., 2011). 


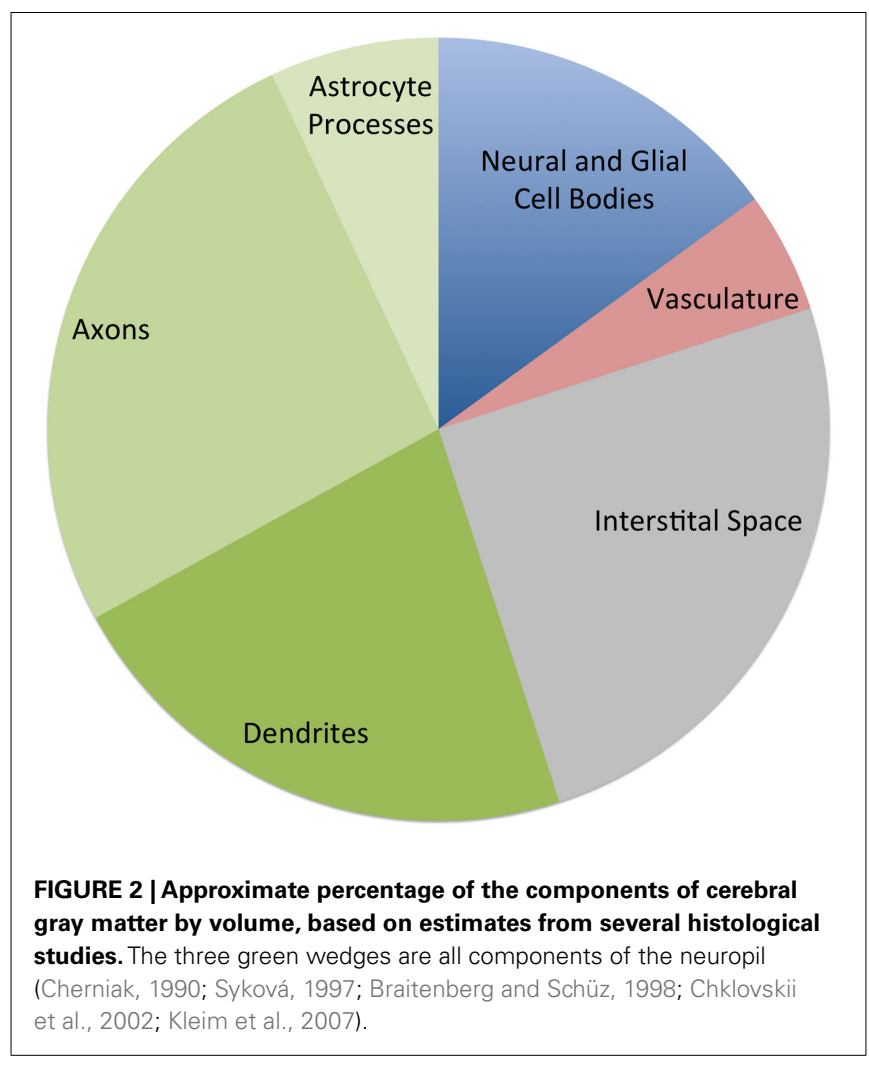

subsequent studies using different quantification methods have reported increases from $50 \%$ to over $1000 \%$. If these measures are accurate they could account for the gray matter changes discussed above entirely within the vascular compartment.

A recent study using a small sample of macaques replicated the increase in vascular volume fraction in motor cortex with 5 months of daily treadmill exercise. Interestingly, this effect was found only in older animals (15-17 years old) while middle-aged animals (10-12 years old) showed no change in vascular volume fraction (Rhyu et al., 2010).

The mechanism by which aerobic exercise results in increased angiogenesis in the brain is not fully understood. It is believed that mechanical sheer stress on the walls of the capillaries as well as a reduction in the degree of blood oxygenation (hypoxia) may play a role (Makanya et al., 2009). Independent of exercise, hypoxia itself is a potent stimulus of angiogenesis in the brain. Patt et al. (1997) demonstrated that rats exposed to progressive amounts of hypoxia over 130 days showed angiogenesis in a wide variety of brain areas including cerebral cortex, striatum, and hippocampus. Differences in capillary density in cerebellum and the medulla oblongata failed to reach significance due to the high variability in baseline vascular density in control animals. Contrary to Isaacs et al. (1992), Patt and colleagues also found increases in capillary diameter in cerebral cortex and cerebellum. Such changes could potentially also occur in association with the mild hypoxia that can occur during aerobic activity. Differences in vessel diameter associated with aerobic activity have also been shown in a magnetic resonance angiography study of elderly human individuals (Bullitt et al., 2009).
A considerable amount of work has looked at angiogenesis in the hippocampus; however, these studies have focused on the tight relationship between angiogenesis and the growth of new neurons. This work will be discussed in more detail below.

\section{GLIA}

As revealed in the graph above, astrocytes and other glial cells consume a significant proportion of neuropil volume. While glial cells are similar to the vasculature compartment in that they play an important role in the metabolic support of neurons, they also have an active role in regulating the efficacy of synapses and even directly communicating with neurons via calcium signaling (see Zhang and Haydon, 2005 for a review). Given these dual roles, we might expect astrocytes to behave like neural processes and expand their volume only in response to learning. Alternatively, we might expect them to behave more like vasculature and respond to both exercise and learning. Anderson et al. (1994) addressed this question in rat cerebellar cortex by measuring the volume of astrocytes after a period of motor learning or voluntary exercise. The study showed that while the overall density of glial processes did not differ between groups, the glial volume per purkinje cell in rats in the motor learning condition was significantly greater than that of rats exposed to voluntary exercise alone. The motor learning group also showed an overall increase in the volume of the molecular layer. This suggests that the astroglia are more similar to the synaptic and neural structure than they are to vasculature in their pattern of growth.

\section{NEUROGENESIS}

New neurons are generated in the vertebrate brain throughout the life span. (See Colucci-D'Amato and di Porzio, 2008 for an account of the rise and fall of the "no new neurons" dogma over the course of the twentieth century). There is general agreement that neurogenesis occurs in two areas of the mammalian brain: the sub-granular zone of the dentate gyrus within the hippocampus and the subventricular zone located in the lateral ventricles. Neurogenesis in the hippocampus, like angiogenesis, has been shown to increase with physical activity (van Praag et al., 1999a), but the creation of new neurons in the hippocampus is a delicate process. A large fraction of the new neurons created do not survive (Kempermann et al., 2010). Kronenberg et al. (2003) showed that while exercise increases the rate of neurogenesis, environmental enrichment increases the ratio of new neurons that survive and get incorporated into the lattice of the existing neural network.

Some studies have suggested that both new neural cells and new endothelial cells (used to build new capillaries) derive from the same pool of stem cells (Palmer et al., 2000). Pereira et al. (2007) demonstrated a correlation between the number of new neurons generated in mouse dentate gyrus and the degree of increase in regional CBV as measured by contrast-enhanced MRI. In a small sample of human subjects, they demonstrated a significant increase in regional cerebral blood volume (rCBV) after 3 months of aerobic exercise. Changes in rCBV were shown to correlate with increases in $\dot{\mathrm{VO}}_{2}$ max scores as well as post-exercise performance on a verbal learning task. The authors argue that 
these data suggest that rCBV can be used as a proxy for measuring neurogenesis in mice as well as humans. This exciting possibility must be reconciled with the fact that there are several regions of the brain in which angiogenesis has been observed, such as the cerebral cortex and cerebellum, which most researchers believe are not capable of neurogenesis. Some authors have argued that neurogenesis does occur in the cerebral cortex (Gould et al., 1999) and in the cerebellum (Carletti and Rossi, 2008). This would provide a possible resolution to this apparent contradiction in Pereira and colleagues' theory. But the idea of neurogenesis outside of the hippocampus and the subventricular zone remains very controversial (Rakic, 2002; Ming and Song, 2005).

\section{WHITE MATTER AND CONNECTIVITY}

The majority of the literature on structural change with aerobic activity has focused on the region of the brain that contains the majority of cell bodies, synaptic connections and vasculature, i.e., the "gray matter." The effects of exercise on "white matter," the large mass of mostly myelinated axons near the center of the brain, have been overlooked until very recently. An early attempt to look at white matter volume was conducted by Colcombe et al. (2004) using VBM techniques on segmented white matter images. They reported an anterior cluster of increased white matter after 6 months of exercise in a group of elderly adults. However, the use and interpretation of VBM on white matter volumes are somewhat controversial (Draganski et al., 2006; Smith et al., 2006).

The past 5-10 years have witnessed significant advancements in our ability to study the connectivity between brain areas embodied by the white matter. The advent and popularization of diffusion tensor imaging (DTI) have allowed researchers to study the structural integrity of white matter directly (see Johansen-Berg, 2010 for review). Concurrently, another area of study known as "functional connectivity" has grown in popularity and sophistication. This technique uses functional MRI data to explore temporal correlations between brain areas (see Smith et al., 2011 for review). The strength of these correlations is thought to provide a measure of the degree to which different regions of the brain are working in concert as a "functional network."

DTI changes associated with aerobic activity have recently been examined in a 1-year fitness training study on elderly adults. Heo and Kramer (2010) show a correlation between white matter integrity and changes in $\dot{\mathrm{VO}}_{2}$ max scores in frontal and temporal white matter tracts. Interestingly, the change in white matter integrity for the aerobic training group did not significantly differ from a control group that participated in 1 year of nonaerobic exercise, suggesting that aspects other than aerobic exercise contributed to the observed change. Differences in resting functional connectivity associated with fitness level were reported in a recent study by Voss et al. (2010). Aging has been previously shown to result in a decrease of functional connectivity in the so-called "default mode network" (DMN, Andrews-Hanna et al., 2007). The DMN is a well-studied set of brain regions that show a decrease in activity when external processing demands are increased. Voss and colleagues demonstrate that some of the functional connections within the DMN (particularly the connection between the posterior cingulate gyrus and the middle frontal gyrus) exhibit a positive correlation with $\dot{\mathrm{V}}_{2}$ max score, controlling for age. They also demonstrated several positive correlations between functional connectivity and cognitive measures of executive function and spatial memory.

\section{BIOCHEMICAL MECHANISMS}

Complex biochemical cascades are responsible for building new vascular and neural structure in the brain. Detailed discussion of these cascades is beyond the scope of this review (see Olson et al., 2006; Zhao et al., 2008; Erickson et al., 2012), however two important and well-studied growth factors bare a brief discussion. Brain derived neurotrophic factor (BDNF) and vascular endothelial growth factor (VEGF) are both are up regulated with exercise. BDNF synthesis is triggered by a local increase in neural activity while VEGF production is triggered by hypoxia (Shweiki et al., 1992; Goodman et al., 1996). BDNF triggers an intracellular biochemical cascade that expands neural structures such as dendritic spines and axonal buttons (McAllister et al., 1999). VEGF acts on the endothelial cells lining the wall of the blood vessels triggering them to divide and produce new blood vessels. (Bloor, 2005). Both BDNF and VEGF play important but different roles in neurogenesis. While VEGF promotes the proliferation of new neural progenitor cells inside the neurogenic niche, BDNF promotes their survival and incorporation into the neural architecture. Both VEGF and BDNF polymorphism are associated with depression (NevesPereira et al., 2002; Sklar et al., 2002; Strauss et al., 2005; Viikki et al., 2010). Antidepressant medications cause an increase in BDNF expression, but their effects on VEGF have not yet been clearly demonstrated (Martinowich and Lu, 2008; Ventriglia et al., 2009).

\section{TIME COURSE}

Each of the components of brain plasticity has a unique function and therefore also has a unique temporal profile with respect to the onset and offset of increased aerobic activity. Studies have shown that the primary component of change associated with exercise, i.e., increased capillary density, has a very rapid time course. A recent study in rat hippocampus demonstrates that an increase in capillary density occurs within 3 days of the onset of increased aerobic activity (Van der Borght et al., 2009). Perhaps even more surprisingly, rats removed from the exercise condition returned to baseline levels of capillary density after just $24 \mathrm{~h}$ of sedentary behavior. As discussed above, the creation of new neurons seems to be tightly coupled with angiogenic growth and therefore also follows a time course that rapidly responds to changes in aerobic activity. However, new neurons created over the course of increases in aerobic activity will quickly die off if adequate learning opportunities or novel experiences do not accompany the increased aerobic activity (van Praag et al., 1999b; Kempermann et al., 2010). Astrocytes are also sensitive to the presence of environmental enrichment and will only exhibit volume increases when these stimuli exist (Kleim et al., 2007). However they differ from neurogenic growth in that they return to baseline volume as soon as the animal is removed from the stimulating environment. Synaptic growth in the neuropil is also dependent on learning 
Aerobic Activity with Enrichment

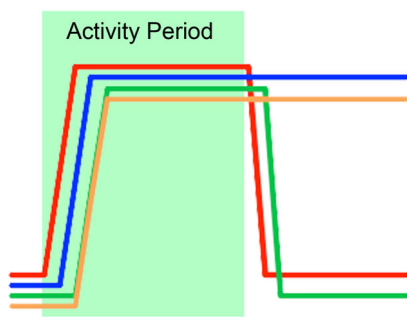

Aerobic Activity Alone

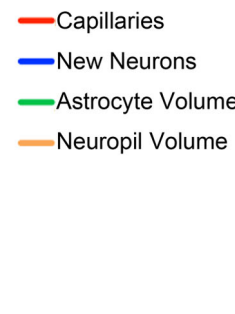

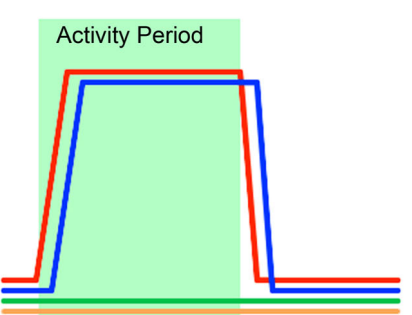

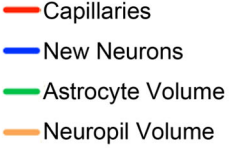

Neuropil Volume

FIGURE 3 | A schematic summary of the time courses of the different components of structural change associated with exercise and environmental enrichment, based on several studies discussed in this review (Black et al., 1990; Kleim et al., 2007; Van der Borght et al., 2009; Kempermann et al., 2010).

or novel experiences, but unlike astrocytes, increases in synaptic density and neuropil volume are relatively persistent. Kleim et al. (1997) demonstrated that increases in synaptic density in cerebellum lasted for at least 4 weeks after animals were removed from an enriched environment.

These studies provide us with a rough idea of the time course of plasticity in the different component of brain architecture as well as the necessary and sufficient conditions for plasticity in each (Figure 3). Vasculature plasticity has a rapid onset, is reliable in both exercise and enrichment conditions, and is quick to return to baseline after the intervention. Neurogenesis is also present across both exercise and enrichment paradigms, but long-lasting only when learning is present. Both astrocyte and neuropil plasticity are only responsive to enrichment, but only astrocyte volume returns to baseline post-intervention.

\section{GROUP SPECIFICITY AND CEILING EFFECTS}

There is a long-standing debate in the literature regarding whether environmental enrichment manipulations can be truly considered "enrichment," or whether they simply represent a modest reprieve from the impoverished environment of a typical laboratory animal (Grossman et al., 2002). This raises the question as to whether reported brain changes can be thought of as enhancements from a typical baseline or a recovery from atrophy. In the human literature the majority of the published work on the effects of exercise on the brain is in participants who may have also experienced brain atrophy due to either age (Erickson et al., 2011) or mental illness (de Lange et al., 2008; Pajonk et al., 2010). Podewils et al. (2005) provide a counter-example of one at-risk population that does not seem to benefit from exercise. In a large epidemiological study of older participants, they show that while level of fitness is protective against the onset of dementia and Alzheimer's disease across

\section{REFERENCES}

Aberg, M. A. I., Pedersen, N. L., Torén, K., Svartengren, M., Bäckstrand, B., Johnsson, T., Cooper-Kuhn, C. M., Aberg, N. D., Nilsson, M., and Kuhn, H. G. (2009). Cardiovascular fitness is associated with cognition in

the entire population, carriers of the apolipoprotein E genotype (APOE) e 4 allele, which is associated with increased dementia risk, show no association between fitness level and dementia risk. This finding suggests that aerobic activity cannot rescue individuals from the increased risk incurred by this genotype.

Although relatively few studies exist on the effects of aerobic activity on the brain structure of healthy, younger individuals, there is a wealth of data demonstrating the cognitive benefits of frequent aerobic exercise throughout the lifespan - perhaps none more convincing than a recent study of 1.2 million Swedish military conscripts that showed a strong correlation between fitness and intelligence (Aberg et al., 2009). Much work remains to be done to determine what level of aerobic activity is required for cognitive and brain health to be maximized, but it seems likely this level is well above that of the average individual.

\section{CONCLUSION}

The study of the effects of exercise on brain structure and cognition is still in its infancy. The research reviewed here by and large simply demonstrates that aerobic activity is indeed a powerful modulator of structural brain plasticity. The precise components and time course of exercise-mediated changes in brain structure are beginning to be delineated, but many unanswered questions remain. In particular, the key ingredients of an exercise intervention for triggering specific aspects of structural brain changes are yet to be determined. In addition, individual differences in lifestyle, genetics, and physiology are likely to have significant influence on exercise effects, but this influence is poorly understood as of yet. Future studies may demonstrate the potential of exercise as a tool to remediate a variety of debilitating diseases as well as to maximize cognitive potential in development or to lessen the burden of cognitive decline associated with aging.

but not with angiogenesis following exercise. Glia 11, 73-80.

Andrews-Hanna, J. R., Snyder, A. Z., Vincent, J. L., Lustig, C., Head, D., Raichle, M. E., and Buckner, R. L. (2007). Disruption of large-scale brain systems in advanced aging. Neuron 56, 924-935.

Arnold, S. E., and Rioux, L. (2001). Challenges, status, and opportunities for studying developmental neuropathology in adult schizophrenia. Schizophr. Bull. 27, 395-416. 
Åstrand, P.-O., Rodahl, K., Dahl, H. A., and Stromme, S. B. (2003). Textbook of Work Physiology-4th: Physiological Bases of Exercise, 4th Edn. Champaign: Human Kinetics, 656.

Black, J., Isaacs, K., Anderson, B., Alcantara, A., and Greenough, W. (1990). Learning causes synaptogenesis, whereas motor activity causes angiogenesis, in cerebellar cortex of adult rats. Proc. Natl. Acad. Sci. U.S.A. 87, 5568-5572.

Bloor, C. M. (2005). Angiogenesis during exercise and training. Angiogenesis 8, 263-271.

Braitenberg, V., and Schüz, A. (1998). Cortex: Statistics and Geometry of Neuronal Connectivity, 2nd Edn. Berlin: Springer, 249.

Bullitt, E., Rahman, F. N., Smith, J. K., Kim, E., Zeng, D., Katz, L. M., and Marks, B. L. (2009). The effect of exercise on the cerebral vasculature of healthy aged subjects as visualized by MR angiography. AJNR Am. J. Neuroradiol. 30, 1857-1863.

Busse, A., Jacob Filho, W., Magaldi, R., and Coelho, V. (2008). Effects of resistance training exercise on cognitive performance in elderly individuals with memory impairment: results of a controlled trial. Einstein 6, 402-407.

Butters, M. A., Young, J. B., Lopez, O., Aizenstein, H. J., Mulsant, B. H., Reynolds, C. F., DeKosky, S. T., and Becker, J. T. (2008). Pathways linking late-life depression to persistent cognitive impairment and dementia. Dialogues Clin. Neurosci. 10, 345-357.

Cancela Carral, J. M., and Ayán Pérez, C. (2007). Effects of high-intensity combined training on women over 65. Gerontology 53, 340-346.

Carletti, B., and Rossi, F. (2008). Neurogenesis in the cerebellum. Neuroscientist 14, 91-100.

Caspersen, C. J., Powell, K. E., and Christenson, G. M. (1985). Physical activity, exercise, and physical fitness: definitions and distinctions for healthrelated research. Public Health Rep. $100,126-131$.

Cassilhas, R. C., Viana, V. A. R., Grassmann, V., Santos, R. T., Santos, R. F., Tufik, S., and Mello, M. T. (2007). The impact of resistance exercise on the cognitive function of the elderly. Med. Sci. Sports Exerc. 39, 1401-1407.

Chaddock, L., Erickson, K. I., Prakash, R. S., Kim, J. S., Voss, M. W., Vanpatter, M., Pontifex, M. B., Raine, L. B., Konkel, A., Hillman, C. H., Cohen, N. J., and Kramer, A. F. (2010). A neuroimaging investigation of the association between aerobic fitness, hippocampal volume, and memory performance in preadolescent children. Brain Res. 1358, 172-183.

Chen, X., Leischner, U., Rochefort, N. L., Nelken, I., and Konnerth, A. (2011). Functional mapping of single spines in cortical neurons in vivo. Nature $475,501-505$.

Cherniak, C. (1990). The bounded brain: toward quantitative neuroanatomy. J. Cogn. Neurosci. 2, 58-68.

Chklovskii, D. B., Schikorski, T., and Stevens, C. F. (2002). Wiring optimization in cortical circuits. Neuron $34,341-347$.

Colcombe, S., and Kramer, A. F. (2003). Fitness effects on the cognitive function of older adults: a meta-analytic study. Psychol. Sci. 14, 125-130.

Colcombe, S. J., Erickson, K. I., Scalf, P. E., Kim, J. S., Prakash, R., McAuley, E., Elavsky, S., Marquez, D. X., Hu, L., and Kramer, A. F. (2006). Aerobic exercise training increases brain volume in aging humans. J. Gerontol. A Biol. Sci. Med. Sci. 61, 1166-1170.

Colcombe, S. J., Kramer, A. F., Erickson, K. I., Scalf, P., McAuley, E., Cohen, N. J., Webb, A., Jerome, G. J., Marquez, D. X., and Elavsky, S. (2004). Cardiovascular fitness, cortical plasticity, and aging. Proc. Natl. Acad. Sci. U.S.A. 101, 3316-3321.

Colucci-D'Amato, L., and di Porzio, U. (2008). Neurogenesis in adult CNS: from denial to opportunities and challenges for therapy. Bioessays 30 , 135-145.

Cotman, C. W., and Berchtold, N. C. (2002). Exercise: a behavioral intervention to enhance brain health and plasticity. Trends Neurosci. 25, 295-301.

Cotman, C. W., Berchtold, N. C., and Christie, L.-A. (2007). Exercise builds brain health: key roles of growth factor cascades and inflammation. Trends Neurosci. 30, 464-472.

de Lange, F. P., Koers, A., Kalkman, J. S., Bleijenberg, G., Hagoort, P., van der Meer, J. W., and Toni, I. (2008). Increase in prefrontal cortical volume following cognitive behavioural therapy in patients with chronic fatigue syndrome. Brain 131, 21722180.

Ding, Y.-H., Li, J., Zhou, Y., Rafols, J. A., Clark, J. C., and Ding, Y. (2006). Cerebral angiogenesis and expression of angiogenic factors in aging rats after exercise. Curr. Neurovasc. Res. 3, 15-23.

Ding, Y.-H., Young, C. N., Luan, X., Li, J., Rafols, J. A., Clark, J. C., McAllister, J. P., and Ding, Y. (2005). Exercise preconditioning ameliorates inflammatory injury in ischemic rats during reperfusion. Acta Neuropathol. 109, 237-246.

Draganski, B., Gaser, C., Busch, V., Schuierer, G., Bogdahn, U., and May, A. (2004). Neuroplasticity: changes in grey matter induced by training - newly honed juggling skills show up as a transient feature on a brain-imaging scan. Nature 427 , 311-312.

Draganski, B., Gaser, C., Kempermann, G., Kuhn, H. G., Winkler, J., Büchel, C., and May, A. (2006). Temporal and spatial dynamics of brain structure changes during extensive learning. J. Neurosci. 26, 6314-6317.

Erickson, K. I., Miller, D. L., and Roecklein, K. A. (2012). The aging hippocampus: interactions between exercise, depression, and BDNF. Neuroscientist 18, 82-97.

Erickson, K. I., Voss, M. W., Prakash, R. S., Basak, C., Szabo, A., Chaddock, L., Kim, J. S., Heo, S., Alves, H., White, S. M., Wojcicki, T. R., Mailey, E., Vieira, V. J., Martin, S. A., Pence, B. D., Woods, J. A., Mcauley, E., and Kramer, A. F. (2011). Exercise training increases size of hippocampus and improves memory. Proc. Natl. Acad. Sci. U.S.A. 108, 3017-3022.

Erickson, K. I., Prakash, R. S., Voss, M. W., Chaddock, L., Hu, L., Morris, K. S., White, S. M., Wójcicki, T. R., McAuley, E., and Kramer, A. F. (2009). Aerobic fitness is associated with hippocampal volume in elderly humans. Hippocampus 19, 1030-1039.

Flöel, A., Ruscheweyh, R., Krüger, K., Willemer, C., Winter, B., Völker, K., Lohmann, H., Zitzmann, M., Mooren, F., Breitenstein, C., and Knecht, S. (2010). Physical activity and memory functions: are neurotrophins and cerebral gray matter volume the missing link? Neuroimage 49, 2756-2763.

Goodman, L. J., Valverde, J., Lim, F., Geschwind, M. D., Federoff, H. J. Geller, A. I., and Hefti, F. (1996). Regulated release and polarized localization of brain-derived neurotrophic factor in hippocampal neurons. Mol. Cell. Neurosci. 7, 222-238.

Gould, E., Reeves, A. J., Graziano, M. S., and Gross, C. G. (1999). Neurogenesis in the neocortex of adult primates. Science 286, 548-552.

Grossman, A. W., Churchill, J. D., Bates, K. E., Kleim, J. A., and Greenough, W. T. (2002). A brain adaptation view of plasticity: is synaptic plasticity an overly limited concept? Prog. Brain Res. 138, 91-108.

Haskell, W. L., Lee, I.-M., Pate, R. R., Powell, K. E., Blair, S. N., Franklin,
B. A., Macera, C. A., Heath, G. W., Thompson, P. D., and Bauman, A. (2007). Physical activity and public health: updated recommendation for adults from the American College of Sports Medicine and the American Heart Association. Med. Sci. Sports Exerc. 39, 1423-1434.

Heo, S., and Kramer, A. F. (2010). The Influence of Aerobic Fitness on Cerebral White Matter Integrity and Cognitive Function in Older Adults: Results of a One-Year Exercise Intervention. Master's thesis. University of Illinois at Urbana-Champaign, Urbana-Campaign.

Herculano-Houzel, S., Mota, B., and Lent, R. (2006). Cellular scaling rules for rodent brains. Proc. Natl. Acad. Sci. U.S.A. 103, 12138-12143.

Isaacs, K. R., Anderson, B. J., Alcantara, A. A., Black, J. E., and Greenough, W. T. (1992). Exercise and the brain: angiogenesis in the adult rat cerebellum after vigorous physical activity and motor skill learning. J. Cereb. Blood Flow Metab. 12, 110-119.

Johansen-Berg, H. (2010). Behavioural relevance of variation in white matter microstructure. Curr. Opin. Neurol. 23, 351-358.

Kempermann, G., Fabel, K., Ehninger, D., Babu, H., Leal-Galicia, P., Garthe, A., and Wolf, S. A. (2010). Why and how physical activity promotes experience-induced brain plasticity. Front. Neurosci. 4:189. doi:10.3389/fnins.2010.00189

Kim, J. J., and Diamond, D. M. (2002). The stressed hippocampus, synaptic plasticity and lost memories. Nat. Rev. Neurosci. 3, 453-462.

Kleim, J., Lussnig, E., Schwarz, E., Comery, T., and Greenough, W. (1996). Synaptogenesis and FOS expression in the motor cortex of the adult rat after motor skill learning. J. Neurosci. 16, 4529-4535.

Kleim, J., Markham, J., Vij, K., Freese, J., Ballard, D., and Greenough, W. (2007). Motor learning induces astrocytic hypertrophy in the cerebellar cortex. Behav. Brain Res. 178, 244-249.

Kleim, J. A., Barbay, S., Cooper, N. R., Hogg, T. M., Reidel, C. N., Remple, M. S., and Nudo, R. J. (2002a). Motor learning-dependent synaptogenesis is localized to functionally reorganized motor cortex. Neurobiol. Learn. Mem. 77, 63-77.

Kleim, J. A., Cooper, N. R., and VandenBerg, P. M. (2002b). Exercise induces angiogenesis but does not alter movement representations within rat motor cortex. Brain Res. 934, 1-6.

Kleim, J. A., Vij, K., Ballard, D. H., and Greenough, W. T. (1997). 
Learning-dependent synaptic modifications in the cerebellar cortex of the adult rat persist for at least four weeks. J. Neurosci. 17, 717-721.

Kramer, A. F., and Erickson, K. I. (2007). Capitalizing on cortical plasticity: influence of physical activity on cognition and brain function. Trends Cogn. Sci. (Regul. Ed.) 11, 342-348.

Kronenberg, G., Reuter, K., Steiner, B., Brandt, M. D., Jessberger, S., Yamaguchi, M., and Kempermann, G. (2003). Subpopulations of proliferating cells of the adult hippocampus respond differently to physiologic neurogenic stimuli. J. Comp. Neurol. 467, 455-463.

Lachman, M. E., Neupert, S. D., Bertrand, R., and Jette, A. M. (2006). The effects of strength training on memory in older adults. J. Aging Phys. Act. 14, 59-73.

Makanya, A. N., Hlushchuk, R., and Djonov, V. G. (2009). Intussusceptive angiogenesis and its role in vascular morphogenesis, patterning, and remodeling. Angiogenesis 12, 113-123.

Markham, J., and Greenough, W. T. (2004). Experience-driven brain plasticity: beyond the synapse. $\mathrm{Neu}-$ ron Glia Biol. 1, 351-363.

Martinowich, K., and Lu, B. (2008). Interaction between BDNF and serotonin: role in mood disorders. Neuropsychopharmacology 33, 73-83.

McAllister, A. K., Katz, L. C., and Lo, D. C. (1999). Neurotrophins and synaptic plasticity. Annu. Rev. Neurosci. 22, 295-318.

McClelland, J. L., McNaughton, B. L., and O'Reilly, R. C. (1995). Why there are complementary learning systems in the hippocampus and neocortex: insights from the successes and failures of connectionist models of learning and memory. Psychol. Rev. 102, 419-457.

Ming, G.-L., and Song, H. (2005). Adult neurogenesis in the mammalian central nervous system. Annu. Rev. Neurosci. 28, 223-250.

Neves-Pereira, M., Mundo, E., Muglia, P., King, N., Macciardi, F., and Kennedy, J. L. (2002). The brainderived neurotrophic factor gene confers susceptibility to bipolar disorder: evidence from a familybased association study. Am. J. Hum. Genet. 71, 651-655.

Olson, A. K., Eadie, B. D., Ernst, C., and Christie, B. R. (2006). Environmental enrichment and voluntary exercise massively increase neurogenesis in the adult hippocampus via dissociable pathways. Hippocampus 16, 250-260.
Pajonk, F.-G., Wobrock, T., Gruber, O., Scherk, H., Berner, D., Kaizl, I., Kierer, A., Müller, S., Oest, M., Meyer, T., Backens, M., Schneider-Axmann, T., Thornton, A. E., Honer, W. G., and Falkai, P. (2010). Hippocampal plasticity in response to exercise in schizophrenia. Arch. Gen. Psychiatry 67, 133-143.

Palmer, T. D., Willhoite, A. R., and Gage, F. H. (2000). Vascular niche for adult hippocampal neurogenesis. J. Comp. Neurol. 425, 479-494.

Patt, S., Sampaolo, S., Théallier-Jankó, A., Tschairkin, I., and CervósNavarro, J. (1997). Cerebral angiogenesis triggered by severe chronic hypoxia displays regional differences. J. Cereb. Blood Flow Metab. 17, 801-806.

Pearson-Fuhrhop, K. M., Kleim, J. A., and Cramer, S. C. (2009). Brain plasticity and genetic factors. Top. Stroke Rehabil. 16, 282-299.

Pereira, A., Huddleston, D., Brickman, A., Sosunov, A., Hen, R., McKhann, G., Sloan, R., Gage, F., Brown, T., and Small, S. (2007). An in vivo correlate of exercise-induced neurogenesis in the adult dentate gyrus. Proc. Natl. Acad. Sci. U.S.A. 104, 5638-5643.

Podewils, L. J., Guallar, E., Kuller, L. H., Fried, L. P., Lopez, O. L., Carlson, M., and Lyketsos, C. G. (2005). Physical activity, APOE genotype, and dementia risk: findings from the Cardiovascular Health Cognition Study. Am. J. Epidemiol. 161, 639-651.

Prior, B. M., Yang, H. T., and Terjung, R. L. (2004). What makes vessels grow with exercise training? J. Appl. Physiol. 97, 1119-1128.

Rakic, P. (2002). Neurogenesis in adult primate neocortex: an evaluation of the evidence. Nat. Rev. Neurosci. 3, 65-71.

Rhyu, I. J., Bytheway, J. A., Kohler, S. J., Lange, H., Lee, K. J., Boklewski, J., McCormick, K., Williams, N. I., Stanton, G. B., Greenough, W. T., and Cameron, J. L. (2010). Effects of aerobic exercise training on cognitive function and cortical vascularity in monkeys. Neuroscience 167, 1239-1248.

Ruscheweyh, R., Willemer, C., Krüger, K., Duning, T., Warnecke, T., Sommer, J., Völker, K., Ho, H. V., Mooren, F., Knecht, S., and Flöel, A. (2011). Physical activity and memory functions: an interventional study. Neurobiol. Aging 32, 1304-1319.

Sarko, D. K., Catania, K. C., Leitch, D. B., Kaas, J. H., and Herculano-Houzel, S. (2009). Cellular scaling rules of insectivore brains. Front. Neuroanat. 3:8. doi:10.3389/neuro.05.008.2009

Scholz, J., Klein, M., Behrens, T., and Johansen-Berg, H. (2009). Training induces changes in whitematter architecture. Nat. Neurosci. 12, 1370-1371.

Shweiki, D., Itin, A., Soffer, D., and Keshet, E. (1992). Vascular endothelial growth factor induced by hypoxia may mediate hypoxiainitiated angiogenesis. Nature 359 843-845.

Sklar, P., Gabriel, S. B., McInnis, M. G., Bennett, P., Lim, Y.-M., Tsan, G., Schaffner, S., Kirov, G., Jones, I., Owen, M., Craddock, N. DePaulo, J. R., and Lander, E. S. (2002). Family-based association study of 76 candidate genes in bipolar disorder: BDNF is a potential risk locus. Brain-derived neutrophic factor. Mol. Psychiatry 7 579-593.

Small, S. A., Schobel, S. A., Buxton, R. B., Witter, M. P., and Barnes, C. A. (2011). A pathophysiological framework of hippocampal dysfunction in ageing and disease. Nat. Rev. Neurosci. 12, 585-601.

Smiley-Oyen, A. L., Lowry, K. A., Francois, S. J., Kohut, M. L., and Ekkekakis, P. (2008). Exercise, fitness, and neurocognitive function in older adults: the "selective improvement" and "cardiovascular fitness" hypotheses. Ann. Behav. Med. 36, 280-291.

Smith, P. J., Blumenthal, J. A., Hoffman, B. M., Cooper, H., Strauman, T. A., Welsh-Bohmer, K. Browndyke, J. N., and Sherwood, A. (2010). Aerobic exercise and neurocognitive performance: a metaanalytic review of randomized controlled trials. Psychosom. Med. 72 239-252.

Smith, S. M., Miller, K. L., SalimiKhorshidi, G., Webster, M., Beckmann, C. F., Nichols, T. E., Ramsey, J. D., and Woolrich, M. W. (2011). Network modelling methods for FMRI. Neuroimage 54, 875-891.

Smith, S. M., Jenkinson, M., JohansenBerg, H., Rueckert, D., Nichols, T. E., Mackay, C. E., Watkins, K. E., Ciccarelli, O., Cader, M. Z., Matthews, P. M., and Behrens, T. E. J. (2006). Tract-based spatial statistics: voxelwise analysis of multisubject diffusion data. Neuroimage 31, 1487-1505.

Steffens, D. C., Byrum, C. E., McQuoid, D. R., Greenberg, D. L., Payne, M. E., Blitchington, T. F., MacFall, J. R., and Krishnan, K. R. (2000). Hippocampal volume in geriatric depression. Biol. Psychiatry 48, 301-309.

Strauss, J., Barr, C. L., George, C. J., Devlin, B., Vetró, A., Kiss, E., Baji, I., King, N., Shaikh, S., Lanktree, M., Kovacs, M., and Kennedy, J. L. (2005). Brain-derived neurotrophic factor variants are associated with childhood-onset mood disorder: confirmation in a Hungarian sample. Mol. Psychiatry 10, 861-867.

Swain, R., Harris, A., Wiener, E., Dutka, M., Morris, H., Theien, B., Konda, S., Engberg, K., Lauterbur, P., and Greenough, W. (2003). Prolonged exercise induces angiogenesis and increases cerebral blood volume in primary motor cortex of the rat. Neuroscience 117, 1037-1046.

Syková, E. (1997). The extracellular space in the CNS: its regulation, volume and geometry in normal and pathological neuronal function. Neuroscientist 3 , 28-41.

US Department of Health and Human Services, Centers for Disease Control and Prevention, National Center for Chronic Disease Prevention and Fitness, President's Council on Physical Fitness. (1998). Physical Activity and Health: A Report of the Surgeon General, US Superintendent of Documents. Burlington, MA: Jones \& Bartlett Learning, 278.

Van der Borght, K., Kóbor-Nyakas, D. E., Klauke, K., Eggen, B. J. L., Nyakas, C., Van der Zee, E. A., and Meerlo, P. (2009). Physical exercise leads to rapid adaptations in hippocampal vasculature: temporal dynamics and relationship to cell proliferation and neurogenesis. Hippocampus 19, 928-936.

van Praag, H., Christie, B. R., Sejnowski, T. J., and Gage, F. H. (1999a). Running enhances neurogenesis, learning, and long-term potentiation in mice. Proc. Natl. Acad. Sci. U.S.A. 96 , 13427-13431.

van Praag, H., Kempermann, G., and Gage, F. H. (1999b). Running increases cell proliferation and neurogenesis in the adult mouse dentate gyrus. Nat. Neurosci. 2, 266-270.

Vaynman, S., and Gomez-Pinilla, F (2005). License to run: exercise impacts functional plasticity in the intact and injured central nervous system by using neurotrophins. Neurorehabil. Neural Repair 19, 283-295.

Ventriglia, M., Zanardini, R., Pedrini, L., Placentino, A., Nielsen, M. G., Gennarelli, M., and BocchioChiavetto, L. (2009). VEGF serum 
levels in depressed patients during SSRI antidepressant treatment. Prog. Neuropsychopharmacol. Biol. Psychiatry 33, 146-149.

Viikki, M., Anttila, S., Kampman, O., Illi, A., Huuhka, M., Setälä-Soikkeli, E., Mononen, N., Lehtimäki, T., and Leinonen, E. (2010). Vascular endothelial growth factor (VEGF) polymorphism is associated with treatment resistant depression. Neurosci. Lett. 477, 105-108.

Voss, M. W., Erickson, K. I., Prakash, R. S., Chaddock, L., Malkowski, E., Alves, H., Kim, J. S., Morris, K. S., White, S. M., Wójcicki, T. R., Hu, L.,
Szabo, A., Klamm, E., McAuley, E., and Kramer, A. F. (2010). Functional connectivity: a source of variance in the association between cardiorespiratory fitness and cognition? Neuropsychologia 48, 1394-1406.

Winter, B., Breitenstein, C., Mooren, F. C., Voelker, K., Fobker, M., Lechtermann, A., Krueger, K., Fromme, A., Korsukewitz, C., Floel, A., and Knecht, S. (2007). High impact running improves learning. Neurobiol. Learn. Mem. 87, 597-609.

Zhang, Q., and Haydon, P. G. (2005). Roles for gliotransmission in the nervous system. J. Neural Transm. $112,121-125$
Zhao, C., Deng, W., and Gage, F. H. (2008). Mechanisms and functional implications of adult neurogenesis. Cell 132, 645-660.

Conflict of Interest Statement: The authors declare that the research was conducted in the absence of any commercial or financial relationships that could be construed as a potential conflict of interest.

Received: 21 November 2011; paper pending published: 17 December 2011; accepted: 05 March 2012; published online: 23 March 2012.
Citation: Thomas AG, Dennis A, Bandettini PA and Johansen-Berg H (2012)

The effects of aerobic activity on brain structure. Front. Psychology 3:86. doi: 10.3389/fpsyg.2012.00086

This article was submitted to Frontiers in Movement Science and Sport Psychology, a specialty of Frontiers in Psychology. Copyright $\odot 2012$ Thomas, Dennis, Bandettini and Johansen-Berg. This is an open-access article distributed under the terms of the Creative Commons Attribution Non Commercial License, which permits non-commercial use, distribution, and reproduction in other forums, provided the original authors and source are credited. 